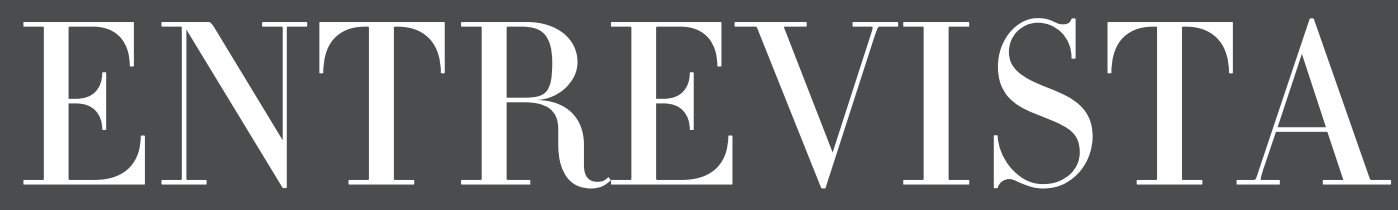




\section{INDICADORES EDUCACIONAIS: ENTREVISTA COM REYNALDO FERNANDES}

\section{GABRIELA MIRANDA MORICONI NELSON GIMENES}

\section{RESUMO}

Nesta entrevista, o professor Reynaldo Fernandes, que trabalhou na criação de indicadores como o Índice de Desenvolvimento da Educação Básica (Ideb) e o Conceito Preliminar de Curso (CPC) durante sua gestão na presidência do Instituto Nacional de Estudos e Pesquisas Educacionais Anísio Teixeira (Inep), discute as opções metodológicas adotadas na construção de indicadores educacionais, suas motivações e propósitos, bem como os seus usos e desdobramentos. Ele destaca, ainda, os avanços já alcançados e os desafios atuais em termos do desenvolvimento e uso de indicadores educacionais no Brasil, bem como as discussões recentes da literatura internacional sobre o tema.

PALAVRAS-CHAVE INDICADORES EDUCACIONAIS - POLÍTICAS EDUCACIONAIS - IDEB • CONCEITO PRELIMINAR DE CURSO • CPC.

\section{INDICADORES EDUCACIONALES: ENTREVISTA CON REYNALDO FERNANDES}

\section{RESUMEN}

En esta entrevista el profesor Reynaldo Fernandes, que trabajó en la elaboración de indicadores como el Índice de Desenvolvimento da Educação Básica (Ideb) y el Conceito Preliminar de Curso (CPC) durante su gestión en la presidencia del Instituto Nacional de Estudos e Pesquisas Educacionais Anísio Teixeira (Inep), discute las opciones metodológicas adoptadas en la construcción de indicadores educacionales, sus motivaciones y propósitos, así como sus usos y desdoblamientos. Destaca asimismo los avances ya alcanzados y los actuales desafios en lo que se refiere al desarrollo y utilización de indicadores educacionales en Brasil, así como las recientes discusiones de la literatura internacional sobre el tema.

PALABRAS CLAVE INDICADORES EDUCACIONALES • POLÍTICAS EDUCACIONALES - IDEB • CONCEPTO PRELIMINAR DE CURSO • CPC.

\section{EDUCATIONAL INDICATORS: AN INTERVIEW WITH REYNALDO FERNANDES}

\section{ABSTRACT}

In this interview, professor Reynaldo Fernandes discusses the methodological choices adopted in the construction of educational indicators, their motivations and purposes, as well as their uses and developments. Professor Fernandes worked on the development of indicators such as the Índice de Desenvolvimento da Educação Básica (Ideb) [Basic Education Development Index] and the Conceito Preliminar de Curso (CPC) [Preliminary Course Concept] during his term as President of the Instituto Nacional de Estudos e Pesquisas Educacionais Anísio Teixeira (Inep) [Anísio Teixeira National Institute of Educational Studies and Research]. He emphasizes the progress already achieved and the current challenges in terms of development and use of educational indicators in Brazil, as well as the recent discussions in the international literature on the subject.

KEYWORDS EDUCATIONAL INDICATORS • EDUCATIONAL POLICIES • IDEB • PRELIMINARY COURSE CONCEPT • CPC. 


\section{APRESENTAÇÃO}

Reynaldo Fernandes é professor da Faculdade de Economia, Administração e Contabilidade de Ribeirão Preto da Universidade de São Paulo (Fearp/USP) desde 1993. De 2010 a 2014, foi membro da Câmara de Educação Superior do Conselho Nacional de Educação. De 2005 a 2009, foi presidente do Instituto Nacional de Estudos e Pesquisas Educacionais Anísio Teixeira (Inep), período no qual - entre outros desafios - trabalhou na criação do Índice de Desenvolvimento da Educação Básica (Ideb) e do conjunto de indicadores da educação superior brasileira. Nesta entrevista, são discutidas as opções metodológicas adotadas na construção de indicadores educacionais, suas motivações e propósitos, bem como os seus usos e desdobramentos. São destacados, ainda, os avanços já alcançados e os desafios atuais em termos do desenvolvimento e uso de indicadores educacionais no Brasil, assim como as discussões recentes da literatura internacional sobre o tema. 
EAE: No Brasil, é relativamente recente o uso de indicadores no planejamento, monitoramento e avaliação de políticas públicas em diversas áreas, em especial nas políticas sociais. Em quais áreas e instâncias de governo você entende que a utilização dos indicadores está mais consolidada? Que condições contribuem para e quais dificultam a adoção de indicadores na gestão das políticas públicas no Brasil?

RF: A cultura de indicadores e avaliações é mais consolidada nas áreas de economia e planejamento, mas avançamos bastante na produção de indicadores em diversas áreas sociais. Produzir indicadores de desempenho é um primeiro passo, mas precisamos ir além. Precisamos criar a cultura de avaliar o impacto de nossas políticas públicas. O problema é que, em geral, aqueles encarregados de conduzir os projetos e políticas públicas não gostam muito de realizar avaliação de impacto. Eles estão comprometidos com as políticas vigentes e há sempre o receio de que elas não apresentem impactos positivos em tais avaliações. Já teve quem sugerisse a criação de uma agência de avaliação independente do governo, no estilo das agências de regulação. Mas há dúvidas sobre a eficiência de um órgão responsável em avaliar políticas públicas nas mais diversas áreas de atuação do setor público.

Talvez o melhor fosse que os encarregados pelas políticas públicas (ministérios, secretarias, etc.) produzissem os indicadores e disponibilizassem os dados para que analistas independentes (em universidades, institutos de pesquisa, organizações sociais, etc.) realizassem as avaliações de impacto. Para isso, é fundamental que os órgãos públicos não dificultem o acesso aos microdados. Infelizmente, pode não ser fácil ter acesso a esses dados, em especial quando eles são produzidos por estados e municípios. Não adianta muito produzir um "caminhão" de dados se eles não estão disponíveis. Por exemplo, não disponibilizar desempenho dos alunos em provas oficiais com base no argumento de que essas notas são confidenciais me parece um exagero. Pesquisadores de outros países têm acesso às notas individuais de alunos e, para isso, precisam apenas escrever uma carta se 
comprometendo a utilizar os dados somente para pesquisa. Temos muito que avançar nesse aspecto.

EAE: Na educação, tanto o Ideb como os indicadores do ensino superior, como o CPC (Conceito Preliminar de Curso) e - IGC (Índice Geral de Cursos), adquiriram um papel central nas políticas públicas. Eles são utilizados não somente para o monitoramento e a avaliação dos sistemas, mas especialmente como principal subsídio para a tomada de decisão em relação a diversas ações do Ministério da Educação (MEC). Os indicadores foram criados com essa função ou esse foi um desdobramento de sua criação? O fato de terem sido definidos como critérios para a tomada de decisões relativas a políticas públicas gera que tipo de consequências para essas políticas e para a gestão dos próprios indicadores?

RF: O Ideb foi criado para ancorar um sistema de metas, enquanto os indicadores do ensino superior surgiram como forma de operacionalizar o Sinaes (Sistema Nacional de Avaliação da Educação Superior). Todos têm em comum o fato de trazerem informações importantes para aqueles que têm que tomar decisões a respeito do assunto (estudantes, pais de alunos, gestores educacionais, etc.). Aqui talvez seja conveniente fazer uma distinção entre avaliação e indicadores educacionais. Enquanto avaliações exprimem um julgamento (expressam uma conclusão normativa acerca da qualidade ou sucesso de estudantes, professores, escolas, programas, políticas ou sistemas educacionais), indicadores podem ter um caráter mais descritivo. Entretanto, a principal função dos indicadores é justamente auxiliar na formação de um juízo avaliativo. Assim, o desempenho médio dos alunos de determinada escola em um exame oficial seria mais propriamente um indicador educacional do que uma avaliação.

Nesse sentido, acredito que os indicadores criados pelo Inep têm cumprido um importante papel na educação brasileira, ainda que alguns exageros tenham sido cometidos, como restringir a oferta de vagas de cursos de ensino superior com base no CPC. 
EAE: Alguns sistemas educacionais optam por divulgar os resultados de suas avaliações e indicadores educacionais somente internamente, para as redes de ensino, escolas e profissionais, utilizando-os para o diagnóstico e monitoramento do desempenho, de modo a orientar políticas educacionais. Outros optam por também divulgar os resultados ao público em geral, com o intuito de mobilizar diferentes atores sociais para que estes cobrem melhorias no ensino ofertado. A última opção foi tomada na criação do Ideb. Quais os motivos para essa opção? Você considera que esses dois propósitos têm sido alcançados? As secretarias de educação têm utilizado os resultados para orientar suas políticas? E as escolas? Você acredita que esse uso, quando existente, tem ocorrido por pressão de pais, alunos e demais atores da sociedade civil?

RF: Como já ressaltado, a ampla divulgação dos resultados auxilia os agentes interessados (professores, gestores, alunos, pais de alunos, etc.) na formação de um juízo mais apropriado sobre a qualidade das escolas e redes de ensino e, desse modo, propicia uma melhoria na educação. A ampla divulgação possibilita, por exemplo, a comparação de resultados entre escolas próximas, que recebem públicos similares. Se duas escolas, apesar de atenderem alunos com o mesmo perfil, apresentam resultados muito distintos nas avaliações, é sinal de que elas têm diferenças na qualidade do ensino oferecido. Uma escola que apresenta resultados inferiores aos de outras que atendem um público parecido deve ser motivo de preocupação. As avaliações com ampla divulgação de resultados propiciam uma mobilização social em prol da melhoria do ensino.

O Ideb é hoje o principal indicador da educação básica. Isso não aconteceria se ele não tivesse uma ampla divulgação e cada escola tivesse acesso apenas ao seu desempenho e ao desempenho médio do país e da sua rede. A avaliação adquire significado pela comparação. Você sabe que sua escola foi bem no Saeb (Sistema de Avaliação da Educação Básica) porque sua média foi 300, enquanto as escolas próximas não passaram de 250 . 
EAE: Já no caso do ensino superior, um dos propósitos dos indicadores existentes também é oferecer informações a potenciais alunos, graduandos, empregadores e sociedade em geral acerca da qualidade dos cursos de graduação. No entanto, a principal função desses indicadores tem sido subsidiar os processos de regulação e supervisão de cursos e IES (instituições de ensino superior) por parte do MEC. Quais os desafios de se trabalhar com indicadores para públicos e funções tão distintas?

RF: Em tese, diferentes indicadores possuem informações distintas que podem ser úteis a todos os interessados: às IES, aos potenciais estudantes e ao regulador. Por exemplo, o desempenho médio dos alunos de determinado curso no Enade (Exame Nacional de Desempenho dos Estudantes) fornece um indicador da qualidade acadêmica média dos egressos do curso. Essa informação auxilia empregadores e potenciais estudantes em suas escolhas. Como a boa qualidade do egresso dá prestígio ao curso e orienta a demanda, a disponibilidade dessa informação incentiva as instituições a melhorarem seu desempenho. Trata-se de uma medida referida à norma, com a qual só podemos afirmar que cursos com melhor desempenho são melhores do que cursos com pior desempenho. Já o Conceito de Curso expressa a opinião dos avaliadores in loco e é uma medida referenciada a critério, na qual o conceito três indica que o curso atende às condições mínimas de funcionamento. Trata-se de uma medida fundamental para o regulador. Por fim, o CPC é uma medida da contribuição do curso para o desempenho de seus alunos no Enade e, nesse sentido, é uma medida de valor adicionado. Como o Enade, trata-se de uma medida referida à norma.

O CPC foi criado para racionalizar as visitas in loco. O Sinaes previa visita in loco para todos os cursos a cada três anos, o que era impraticável. Assim, o CPC surgiu como um indicador preliminar da qualidade do curso. Cursos com conceito três ou mais eram dispensados da visita in loco. O problema é que, a partir de certo momento, o MEC começou a usar o CPC para restringir as matrículas dos cursos. Na minha opinião, trata-se de uso inapropriado do CPC e que não tem nada a ver com a funcionalidade para qual foi criado. 
EAE: Tanto na educação básica, com o Ideb, quanto no ensino superior, com o CPC e o IGC, optou-se por trabalhar com indicadores compostos, em lugar de conjuntos de indicadores simples. Agregar diferentes medidas em um único indicador composto facilita o seu acompanhamento e comparação, mas torna mais complexa a sua compreensão e o seu uso. Quais os motivos para a opção por indicadores compostos, para a avaliação tanto da educação básica como do ensino superior? Como você entende que essa opção afeta o uso dos indicadores por parte dos diferentes atores dos sistemas educacionais e do público em geral?

RF: Essa pergunta permite esclarecer um ponto importante, que nem sempre é observado por aqueles que comentam tais indicadores. Existem dois principais motivos para se adotar um indicador composto. O primeiro motivo é o de considerar diferentes dimensões do problema e resumi-las em um único indicador sintético. Por exemplo, gostaríamos de um indicador que medisse a qualidade das universidades brasileiras, mas as universidades possuem mais de um produto e podemos pensar na qualidade de cada um desses produtos: qualidade do ensino, qualidade da pesquisa e qualidade da extensão universitária. Podemos ainda subdividir cada um desses produtos por áreas de conhecimento e falarmos, por exemplo, em qualidade do ensino em Física, em Direito, em Engenharia, etc. Evidentemente, ao transformar um problema de dimensão $n$ em um indicador de dimensão 1, existe uma perda de informação. Ao produzirmos um indicador sintético desse tipo, temos um ganho de simplicidade em troca de uma perda da riqueza de detalhes. E, mais importante, é preciso dar pesos às diferentes dimensões, o que envolve juízo de valor. Assim, indicadores compostos desse primeiro tipo sempre envolvem um juízo avaliativo. Um exemplo de indicador desse tipo é o IDH (Índice de Desenvolvimento Humano).

O Ideb segue essa orientação. O objetivo era o de ancorar um sistema de metas educacionais; e o receio de considerar apenas o desempenho na Prova Brasil era o de contribuir para agravar o já dramático quadro de repetência e evasão 
1 Trata-se do Texto para Discussão n. 26, intitulado "Índice de Desenvolvimento da Educação Básica", o qual está disponível em: <http://www.publicacoes.inep.gov.br/ portal/download/503 Acesso em: nov. 2016 escolar. Isso por incentivar os professores, diretores e gestores a adotarem medidas que aumentassem tanto o desempenho médio dos estudantes nos testes padronizados quanto as reprovações, endurecendo os critérios para aprovação, por exemplo. Meu texto sobre o Ideb que está publicado em Textos para Discussão do Inep ${ }^{1}$ é, em grande medida, para justificar os pesos adotados para desempenho na Prova Brasil e aprovação.

O segundo motivo para se adotar um indicador composto é que a variável que estamos interessados em medir não seja diretamente observável e que dispomos apenas de medidas imperfeitas dela. Assim, se dispomos de vários indicadores que divergem da "verdadeira" medida de qualidade por um fator de escala e por um erro de medida, poderíamos juntar tais indicadores de modo a minimizar o erro de medida. Então, precisamos de um modelo estatístico que nos auxilie na identificação dos fatores de escala e na forma como os erros de medida se relacionam (em termos técnicos, a matriz de variância e covariância dos erros de medida). Aqui a junção de variáveis não envolve um juízo de valor. É essa a abordagem adotada para o CPC e, indiretamente, para o IGC, que é aproximadamente a média dos CPCs da IES.

O CPC é uma medida de qualidade do curso, entendido como a influência do curso no desempenho de seus alunos no Enade (valor adicionado pela IES), que não é diretamente observável e no qual o conceito Enade, o IDD (Indicador de Diferença dentre os Desempenhos Observado e Esperado) e os insumos considerados são vistos como medidas imperfeitas (sujeitas a erros de medida transitórios e/ou permanentes) dessa qualidade.

Portanto, Ideb, CPC e IGC são indicadores compostos que possuem justificativas totalmente diferentes. Em relação ao Ideb, não creio que essa opção dificulte muito as coisas, pois se trata de um indicador simples. A dificuldade maior se dá em relação ao CPC, por se referir a um indicador de valor adicionado. Existe uma grande demanda por indicadores de valor adicionado por parte dos setores afetados pela avaliação, mas tais indicadores não são de fácil entendimento. 
EAE: Na criação do Ideb, além de trabalhar com indicadores compostos, você explica que, de início, tentou-se estabelecer metas pedagógicas, mas, após escutar diversos especialistas, percebeu-se que seria muito difícil obter um consenso mínimo sobre a questão e optou-se pelo padrão externo, usando os resultados do Pisa (Programme for International Student Assessment). São dois fatores que não se veem em outros países - onde temos conhecimento da existência de metas, elas têm um embasamento pedagógico e usam indicadores isolados, como o percentual de alunos com desempenho adequado (acima de determinado ponto mínimo) e a taxa de conclusão do ensino médio. Você acha que existe um motivo para esses países não fazerem as opções que o Brasil fez? Como essas opções afetam a utilização do Ideb?

RF: O Ideb possui dois componentes: desempenho na Prova Brasil e taxa de aprovação. Para fixação das metas, adotou-se uma taxa de aprovação de 96\%, que era a média dos países da OCDE (Organização para a Cooperação e Desenvolvimento Econômico). A dificuldade foi estabelecer as metas para desempenho na Prova Brasil. A primeira ideia foi definir uma meta pedagógica e, então, encontrar o desempenho na escala do Saeb/Prova Brasil correspondente. Isso se mostrou difícil, não se conseguiu consenso mínimo entre os diversos especialistas consultados. Então, adotamos o desempenho médio dos países da OCDE como referência. Para tanto, admitiu-se que o Pisa ordena os alunos da mesma forma que a Prova Brasil e, então, verificou-se que percentil da distribuição de notas do Brasil no Pisa era correspondente à média de desempenho dos países da OCDE. Encontrado esse percentil, obteve-se a nota correspondente a ele na Prova Brasil de 2005, a qual passou a ser referência para a meta do Ideb.

O problema para definir metas pedagógicas é que não existe algo como conhecimentos e habilidades que possamos considerar natural que estudantes de determinada idade ou série dominem. A princípio, quanto mais os alunos dominam, melhor. No entanto, é preciso ser realista do que é possível esperar que os alunos dominem, e pessoas diferentes podem ter expectativas diferentes. Acho que a saída que 
demos se mostrou bastante razoável e serviu de base para outros sistemas de metas. Usamos um padrão externo, algo já obtido por estudantes de outros países, e demos um prazo razoavelmente longo para atingi-lo.

Acredito que é mais fácil comunicar que queremos atingir a média de desempenho dos países desenvolvidos do que estabelecer que desejamos colocar $70 \%$ dos alunos acima de determinada pontuação. Como afirmado acima, a fixação de níveis como básico, adequado e avançado é arbitrária.

EAE: Na metodologia de seleção dos componentes do CPC, foram utilizados fatores que se mostraram mais correlacionados aos resultados do IDD, como o percentual de professores com título mínimo de doutor. Essa opção também foi por entender que não haveria um consenso pedagógico acerca de quais insumos são importantes para a formação de um aluno no ensino superior? Com o passar do tempo, ao realizar novas análises, é possível que alguns dos componentes já não se mostrem mais associados ao IDD (por exemplo, se a grande maioria dos professores já forem doutores, essa variável não discriminará mais entre os cursos). Deve-se revisar periodicamente as fórmulas de indicadores como o CPC? Como fazê-lo? Como trabalhar possíveis mudanças junto às IES e cursos de modo a não impactar negativamente a qualidade dos cursos?

RF: Como já discutido, tanto os insumos utilizados quantos seus pesos no CPC têm como base um modelo estatístico que visa a reduzir o erro de medida. Evidentemente, um fator com alta correlação com a qualidade de ensino em um momento pode deixar de tê-lo em um outro momento. Então, seria conveniente rever a metodologia de tempos em tempos. É importante que as mudanças sejam anunciadas com certa antecedência para que as IES possam se adequar a elas. Por outro lado, insumos que são amplamente generalizados podem não ter poder explicativo no Enade e, ainda assim, ser importantes. Se todas as IES possuem mais de $90 \%$ de doutores, a participação de doutores não ajudaria a explicar o desempenho diferenciado no Enade, mas isso não significa que as instituições deveriam demitir os doutores. 
EAE: Na formulação do Ideb, observa-se que as metas distintas para redes e escolas foram propostas visando a uma convergência de notas ao longo do tempo, de modo que se reduzam as desigualdades educacionais no país. No entanto, são feitas críticas no sentido de que o índice não contribuiria para o enfrentamento das desigualdades no interior das escolas ou até poderia aumentá-las: ao trabalhar somente com as médias de desempenho e não com a sua distribuição, as escolas poderiam adotar ações voltadas somente para um conjunto de alunos para facilitar o aumento no índice. Essa crítica procede? A possibilidade de inclusão de um fator relativo à desigualdade intraescolar foi considerada na criação do Ideb?

RF: Em tese, essa crítica procede. Na prática, no entanto, para que a meta do Ideb incentive a desigualdade, é preciso considerar que é mais fácil elevar o desempenho daqueles com maior desempenho do que daqueles com menor desempenho no interior das escolas. Isso não é algo comprovado. Ao contrário, estudos sobre a compressão das escalas verticalizadas (como a adotada pela Prova Brasil) entre séries sucessivas sugerem que é mais fácil evoluir na escala quando a pontuação é baixa do que quando a pontuação é mais elevada. Por outro lado, a penalização da repetência tende a afetar mais aqueles com baixo desempenho. Se a repetência não fosse penalizada, a escola poderia reprovar os alunos de pior desempenho e, assim, eles não fariam o Saeb ao final do ciclo. Mas como a repetência é penalizada, a escola é incentivada a dar mais atenção aos alunos que apresentam pior desempenho.

EAE: Diversas pessoas têm recomendado a revisão das metas do Ideb. Argumenta-se que as metas foram estabelecidas com base somente no desempenho das escolas em 2005, dado que era a única medida existente, o que seria muito pouco para metas de longo prazo e, portanto, permitiria um erro muito grande. Argumenta-se também que existem redes que estão muito longe de atingir as metas, em especial as relativas aos anos finais do ensino fundamental e ao ensino médio. Quando as metas se tornam não factíveis, sabe-se que isso impacta o comportamento dos atores envolvidos. Nesse caso, o que poderia ser feito? Quais opções temos? 
RF: Acho que a revisão das metas do Ideb pode ser interessante. Primeiro, elas foram traçadas sem que tivéssemos qualquer experiência em projetar a evolução do desempenho escolar. As avaliações em larga escala são relativamente recentes e os países que aparecem no topo das avaliações internacionais lá já estavam nas primeiras avaliações do Pisa e do TIMSS (Trends in International Mathematics and Science Study). Também é verdade que escolas que foram excepcionalmente mal avaliadas acabaram tendo metas relativamente fáceis, enquanto que escolas que foram excepcionalmente bem avaliadas acabaram tendo metas relativamente mais difíceis. Esse problema, no entanto, restringe-se a escolas individuais e a pequenos municípios.

EAE: Tanto na educação básica como no ensino superior, a evasão de alunos tem se tornado cada vez mais uma preocupação dos atores envolvidos nos sistemas e instituições de ensino. Trata-se de um problema tanto do ponto de vista da garantia do direito à educação quanto da eficiência na alocação dos recursos públicos. No caso da educação básica, um dos componentes do Ideb é a taxa de aprovação, que depende do combate ao abandono e à reprovação. O Ideb não distingue entre abandono e reprovação, os quais podem ser intercambiáveis. Não se fala mais no combate à reprovação do que ao abandono? Faria sentido separá-los? Como? Já no conjunto de indicadores utilizados pelo Governo Federal em relação ao ensino superior, não existem indicadores relativos à conclusão dos cursos de ensino superior ou à evasão de alunos. Quais os motivos? Não deveriam ser criados indicadores voltados para essa temática, considerando a sua utilização tanto para a gestão das instituições federais, como para a regulação e supervisão das demais instituições de ensino superior?

RF: Evidentemente, o Ideb não é perfeito e podemos pensar em várias dimensões importantes do ensino que ele não contempla. Entretanto, uma de suas grandes vantagens é a simplicidade. Acho que ele contempla duas dimensões fundamentais do ensino (aprovação e desempenho na Prova Brasil) e eu não mudaria sua composição. Por exemplo, tratar reprovação 
separado de abandono pode trazer mais desvantagens do que vantagens. Sérgio Costa Ribeiro, no final dos anos 1980, mostrou que, enquanto aprovação é um conceito próximo de progressão de série, não se pode confundir reprovação com repetência de série e abandono com evasão escolar. ${ }^{2}$ No passado, as altas taxas de abandono foram interpretadas como um problema de evasão escolar quando, na verdade, eram um problema de repetência. Os alunos que abandonavam a escola antes do final do ano se matriculavam, no ano seguinte, na mesma série e, portanto, eram repetentes.

Veja, o fato de não incluir no Ideb não significa que não seja importante ter indicadores de repetência e evasão escolar. O mesmo vale para o ensino superior. Possuir indicadores do tempo médio para formação e evasão é, sem dúvida, importante. Isso não significa que devemos colocá-los no CPC. Mudar o CPC requer uma análise mais detalhada.

EAE: No Plano Nacional de Educação (PNE) está previsto o Sistema Nacional de Avaliação da Educação Básica (Sinaeb), o qual deverá produzir "indicadores de rendimento escolar" e também "indicadores de avaliação institucional, relativos a características como o perfil do alunado e do corpo dos(as) profissionais da educação, as relações entre dimensão do corpo docente, do corpo técnico e do corpo discente, a infraestrutura das escolas, os recursos pedagógicos disponíveis e os processos da gestão, entre outras relevantes" (Brasil, 2014, p. 47). ${ }^{3}$ Ou seja, um sistema composto de indicadores de insumo, processo e resultados. Como você entende que um sistema desse tipo deveria ser idealmente? Com que tipos de indicadores? Como devem ser escolhidos? Deve haver um sistema de metas ou deve-se somente acompanhar sua evolução?

RF: Se entendermos um sistema de avaliação da educação básica como um sistema de informações, quanto mais abrangente for esse sistema, melhor. O problema está em querer regular o uso dos indicadores educacionais, ou querer estabelecer um indicador que seja útil para todas as funções para as quais indicadores são utilizados ou ainda que considere todas as dimensões possíveis que definem uma boa
2 As evidências citadas são encontradas em: RIBEIRO, Sérgio Costa. A pedagogia da repetência. Estudos Avançados, v. 5, n. 12, 1991.

3 BRASIL. Câmara dos Deputados. Plano Nacional de Educação 20142024. Lei n. 13.005, de 25 de junho de 2014, que aprova o Plano Nacional de Educação (PNE) e dá outras providências. Brasília, DF: Câmara dos Deputados, Edições Câmara, 2014. 86 p. (Série legislação; n. 125). Disponivel em: <http://www.observatoriodopne. org.br/uploads/reference/file/439/ documento-referencia.pdf>. Acesso em: dez. 2016. 
educação. Isso não existe! É preciso resistir à tentação de achar que há apenas uma forma correta de ler os indicadores educacionais e que nós sabemos qual é essa forma. É só olhar para o debate especializado para ver que diferentes especialistas possuem diferentes leituras de indicadores como o Ideb e o CPC. Quando era presidente do Inep, eu gostava de dizer que o Inep possuía monopólio da produção de certos indicadores, mas não monopólio da interpretação deles.

EAE: Nesse período, após a criação do ldeb e dos indicadores do ensino superior, vimos diversos indicadores sendo propostos, seja por parte do próprio Inep (com os indicadores contextuais), seja por redes estaduais e municipais (com indicadores que partem da mesma base do Ideb, combinando desempenho e fluxo), seja por acadêmicos e outros atores da sociedade civil (com indicadores de infraestrutura, de custo-aluno, entre tantos outros). A que você credita esse aumento na quantidade de indicadores propostos para avaliar diferentes aspectos da educação no país? Houve também uma melhoria na qualidade técnica dos indicadores propostos?

RF: Acho que um elemento importante para essa proliferação de indicadores foi a existência de informações, bem como a melhor formação técnica dos profissionais da área. Em minha opinião, trata-se de um processo natural. Vários indicadores são propostos, alguns vão permanecer e outros não. No entanto, há ainda espaço para avançarmos. Por exemplo, restringir a avaliação do ensino fundamental à Leitura e Matemática parece insuficiente. Além disso, não dispomos de indicadores de valor adicionado na educação básica, que seria outra possibilidade de avanço.

EAE: Os indicadores de qualidade da educação básica e do ensino superior - tanto os oficiais como aqueles propostos por atores externos aos governos - vêm tendo uma grande exposição na mídia. Ainda é um grande desafio que o público se aproprie e faça usos adequados desses indicadores. Houve um avanço na compreensão desses indicadores por parte da sociedade brasileira? Você acredita que os responsáveis por 
esses indicadores têm sido capazes de traduzir esses indicadores em informações que a sociedade compreenda? Os meios de comunicação têm contribuído nessa tarefa?

RF: Temos avançado bastante, mas ainda acho que frequentemente as coberturas dos resultados de indicadores educacionais por parte da mídia são muito simplistas. Entretanto, não há outra saída para avançar mais nessa questão: temos que continuar produzindo e divulgando esses indicadores e incentivar um debate mais intenso sobre o que seus resultados querem dizer. Os produtores desses indicadores devem deixar claro o que o indicador contém e dar sua interpretação sobre a melhor forma de interpretá-lo, mas, novamente, não existe uma única forma de compreendê-lo.

EAE: $O$ que a literatura internacional tem discutido em termos de indicadores educacionais mais recentemente?

RF: Duas discussões me chamam a atenção. A primeira é sobre indicadores de valor adicionado: um indicador frequentemente demandado e fácil de enunciar, mas difícil de realizar. Não há consenso sobre a melhor forma de se obter uma medida de valor adicionado e alguns especialistas consideram que essas medidas são pouco confiáveis, seja por sua grande variabilidade, seja porque elas não estão isentas do problema de viés de seleção (algumas escolas recebem melhores alunos e os modelos de valor adicionado não são capazes de lidar completamente com o problema). Embora vários problemas permaneçam, os avanços dessa literatura são significativos.

A segunda é sobre a avaliação do uso desses indicadores nos chamados programas de accountability educacional. As evidências existentes indicam que a introdução de programas de accountability baseados em resultados dos estudantes em exames padronizados tende a elevar a proficiência dos estudantes nesses exames. Embora uma parte dessa melhora pode dever a uma "inflação de notas", parte da melhora é genuína. Os resultados podem variar bastante a depender do desenho específico do programa e do contexto onde ele é implantado. Por fim, não se deve esperar nenhum milagre 
da introdução desses programas, o que, aliás, é o usual na grande maioria das intervenções em educação.

EAE: Você conhece experiências internacionais interessantes de avaliação do ensino superior, em especial em países com muitas instituições autônomas, como é o caso do Brasil? Trabalham com indicadores? E em relação à educação básica: o que as políticas educacionais voltadas para outros países têm apresentado em termos de indicadores educacionais mais recentemente? Como essas discussões podem ser aproveitadas no contexto brasileiro?

RF: No ensino superior, a discussão sobre avaliação se concentra nos tópicos de avaliação formativa e acreditação. Nos dois casos, ênfase é dada na avaliação in loco, feita por especialistas. Exames como o Enade não são comuns. De qualquer modo, cresce a demanda por uma avaliação mais objetiva e com finalidade de accountability. Na educação básica, o tópico mais quente é o de valor adicionado para professores individuais. Essas medidas são, inclusive, utilizadas na remuneração dos professores. Trata-se, evidentemente, de um ponto polêmico, cujas avaliações ainda não são conclusivas. Sem dúvida, olhar essas experiências pode ser importante para evitar que incorramos nos mesmos erros cometidos por esses países. Por exemplo, atrelar o salário dos professores a uma medida de valor adicionado pode ser muito complicado, uma vez que tais medidas estão sujeitas a muito ruído.

\section{GABRIELA MIRANDA MORICONI}

Pesquisadora da Fundação Carlos Chagas (FCC), São Paulo, São Paulo, Brasil

gmoriconi@fcc.org.br

\section{NELSON GIMENES}

Pesquisador da Fundação Carlos Chagas (FCC). Professor da Pontifícia Universidade Católica de São Paulo (PUC/SP), São Paulo, São Paulo, Brasil

ngimenes@fcc.org.br 
